\title{
]jfis
}

\section{A Proposed Fuzzy Model for Reducing the Risk of Insolvent Loans in the Credit Sector as Applied in Egypt}

\author{
Noha Ibrahem Hasan ${ }^{1}$, Haitham Elghareeb ${ }^{2}$, Farahat Farag Farahat ${ }^{1}$, Ahmed \\ AboElfotouh ${ }^{2}$ \\ ${ }^{1}$ Department of Information System, Sadat Academy for Administration Science, Cairo, Egypt \\ ${ }^{2}$ Faculty of Computers and Information Sciences, Mansoura University, Mansoura, Egypt
}

\begin{abstract}
Non-financial analysis is one of the varied crucial directive tools of credit study that is used for judging whether the client has a genuine desire to pay the assigned amounts of the loan at its maturity dates. Fuzzy logic can help to solve the problem of dealing with factors of non-financial analysis by converting the linguistic variables to numerical variables to calculate their accuracy. This study proposes a fuzzy model that contains a complete database of non-financial factors used by the decision-maker using a fuzzy logic technique, which helps in building the fuzzy rules with great accuracy and helps in predicting the actual situation of the client. In addition, it provides constant following-up of the uses of the granted loan to guarantee that all terms set by the bank are met so that the bank can avoid future defaulting of the client. The proposed model is applied in the credit department of a private Egyptian bank (QNB), with random samples of previous real clients. Some real standards are set to calculate non-financial factors that are related to the client, management, economic situation, and project activity. The results of the proposed model revealed that the correlation factor is 95.3\% between real successful payment clients and successful model clients. To guarantee the accuracy of the knowledge base quality and validation, the knowledge model was presented to the credit manager of the bank under study (expert), who provided a full evaluation of the results of the proposed model compared to the actual situation of clients.
\end{abstract}

Keywords: Credit risk, Non-performing loans, Fuzzy information systems, Knowledge base, Decision making

Received: Jun. 4, 2020

Revised : Jan. 9, 2021

Accepted: Jan. 22, 2021

Correspondence to: Noha Ibrahem Hasan (noha.hassan2020@sadatacademy.edu.eg) ( T) The Korean Institute of Intelligent Systems

(c) This is an Open Access article distributed under the terms of the Creative Commons Attribution Non-Commercial License http://creativecommons.org/licenses/by-nc / 3.0/) which permits unrestricted noncommercial use, distribution, and reproduction in any medium, provided the original work is properly cited.

\section{Introduction}

In the Egyptian banking sector, insolvent loans are the most significant risk that banks encounter. The ratio of non-performing loans and facilities to total loans was $9.1 \%$ at the end of June 2018 [1].

Egyptian banks use traditional models that contain generally accepted statistical rules and methods while specifically examining the case of the client who wants to obtain a loan. Other banks have suffered from large losses during the retrieval of these loans due to the failure of these models to accurately predict the actual situation of the client's repayment, which led to their failure to repay the loan installments on time.

The problem of complexity of the nature of non-financial and credit behavior makes it hard 
to predict the rate of credit inflation accurately [1]. In its report issued on August 28, 2018 [2], Moody's had changed expectations about Egypt's long-term export ratings from stable to positive and had affirmed the $\mathrm{B} 3$ issuer ratings.

Consequently, it has been the best score since 2011, when Egypt received a ?Ba2? ranking, reflecting that Egypt is able to repay liabilities and the banks are somewhat successful in controlling the problem of loan default [2].

Loans become non-performing when they cannot be recovered within a certain stipulated time, which is governed by bank's respective laws. Decision-making is relevant to how to deal with these loans for maximum possible repayment of loans but becomes a difficult and discretionary process.

Fuzzy logic is a technique of artificial intelligence that simulates a decision-making method in humans. It involves all the median possibilities between numerical values. It is a good technique to deal with linguistic variables and convert them to numerical variables to reach the most accurate result.

The researchers used the fuzzy logic technique because it is built by depending on an expert's opinion and on historical data, and also for its ability to deal with factors of non-financial analysis by converting the linguistic variables to numerical variables to calculate them accurately. Thus, the researchers prefer the fuzzy logic technique to the deep learning technique.

Fuzzy knowledge can help to determine the borrower who will be late or default on the monthly installments and enable the lender to take the right steps to prevent financial losses [3].

\section{Literature Review}

In [4], a fuzzy logic model is presented, which is used to assist in determining and predicting bank credit risk rating. For Egyptian banks, it depends on the financial ratios used to assign their credit risk rating. The model presented a good effectiveness in predicting the credit risk rating in banks with a reasonable accuracy. It also presented a set of financial indicators that can be used in the assessment of the bank credit risk rating. Results revealed that the fuzzy logic technique is more scalable, reliable, stable, and different from classical methods.

In [5], the researcher applied the fuzzy logic model as a supporting tool for evaluation of the client's situation, with a major goal to develop a new expert decision-making regarding corporate clients in a bank under. Experts reviewed the types of soft variables used for credit risk assessment of corporate clients and provided the inputs for generating membership functions of these. The results presented a new approach for corporate clients' soft data usage/assessment in commercial banking with an aim of finally being incorporated into a new and superior soft-hard data fusion model.

In [6], the researcher proposed a hybrid system that used neural networks to build a model based on learning abilities and put it into a fuzzy inference module for loan risk evaluation. It is based on an accuracy of forecasting loan risks and measures of average absolute deviation. The results indicated that the hybrid decision support system would decrease the risk often associated with granting loans to clients as well as providing an objective evaluation source for banks.

In [7], a fuzzy logic was introduced to evaluate retail loans that can be used to describe imprecise data or human subjective judgment using linguistic terms. It was based on information inputs used by banks to evaluate a retail loan. The fuzzy inputs were the loan applicant's income level, credit history, character, collateral, and employment with linguistic terms such as "low," "medium," "high," and so on. The model's knowledge base consisted of a rule base of "IF...Then" rules. The output of the model was credit standing, which was also a fuzzy variable with linguistic terms.

After reviewing a number of previous studies in the same field, the researchers suggest that fuzzy logic techniques have been used in a small specific part related to the type of credit provided by banks. This can be attained only by using the financial indicators that are always clearly presented in the client's financial statements. This study presents all types of loans that the bank offers to clients, especially medium- and long-term loans, which are always the cause of a client's financial failure due to the length of the period of repayment of the loan. Some non-financial rules for obtaining the loan, which are difficult to measure with regular equations, such as staff experience, client behavior, marketing skills, product type, and so on, are used.

All of these factors are collected and a knowledge base of "IF...Then" rules is created to help the decision maker select the right financial and loan decision. Most tasks requiring intelligent behavior have some degree of uncertainty associated with them. This type of uncertainty that can occur in knowledgebased systems may be caused by problems with data, for example data may be missing or unavailable, or representation of the data may be imprecise or inconsistent.

The researchers use the fuzzy knowledge base with certainty factors as a method of handling uncertainty of the rules. A certainty factor is a method of dealing with uncertainty and was originally developed for the MYCIN system [8]. 


\subsection{Reasoning Under Uncertainty}

The theory of probability states that:

$$
\mathrm{P}(\mathrm{H})+\mathrm{P}\left(\mathrm{H}^{\prime}\right)=1
$$

and so

$$
\mathrm{P}(\mathrm{H})=1-\mathrm{P}\left(\mathrm{H}^{\prime}\right)
$$

In MYCIN, the certainty factor (CF) was originally defined as the difference between belief and disbelief.

$$
\mathrm{CF}(\mathrm{H}, \mathrm{E})=\mathrm{MB}(\mathrm{H}, \mathrm{E})-\mathrm{MD}(\mathrm{H}, \mathrm{E}) .
$$

where, $\mathrm{CF}$ is the certainty factor in the hypothesis $\mathrm{H}$ due to evidence $\mathrm{E} ; \mathrm{MB}$ is the measure of increased belief in $\mathrm{H}$ due to $\mathrm{E}$; and MD is the measure of increased disbelief in $\mathrm{H}$ due to $\mathrm{E}$.

CFs for the rules have many conditions items [9]:

For the Unified Rules:

IF

AND

AND $<$ Evidence E3 $>$

AND $<$ Evidence En $>$

THEN $<$ Hypothesis $\mathrm{H}>\{\mathrm{cf}\}$

$$
\begin{aligned}
& \mathrm{CF}(\mathrm{H}, \mathrm{E} 1 \cap \mathrm{E} 2 \cap \mathrm{E} 3 \cap \cdots \cap \mathrm{En}) \\
& =\operatorname{Min}[\operatorname{cf}(\mathrm{E} 1), \operatorname{cf}(\mathrm{E} 2), \operatorname{cf}(\mathrm{E} 3), \cdots, \operatorname{cf}(\mathrm{En})] \times \mathrm{CF} .
\end{aligned}
$$

The $\mathrm{CF}$ for each rule is calculated according to the value that is determined by the (QNB) bank's expert, and the linguistic variables table using $\mathrm{CF}$ for unified rules.

\subsection{Defuzzification Subsystem}

Defuzzification is the process of obtaining a single number from the output of the aggregated fuzzy set. It is used to transfer fuzzy inference results into a crisp output (Figure 1).

Defuzzification is realized by a decision-making algorithm that selects the best crisp value based on a fuzzy set. There are several forms of defuzzification including center of gravity $(\mathrm{CoG})$, mean of maximum (MOM), and center average methods.

Several methods exist in the literature to perform defuzzification, the most popular of which is the CoG method, which derives a single crisp numeric value to best represents the inferred fuzzy values of the linguistic output variable. For discrete triangular linear functions, the CoG method is obtained by the

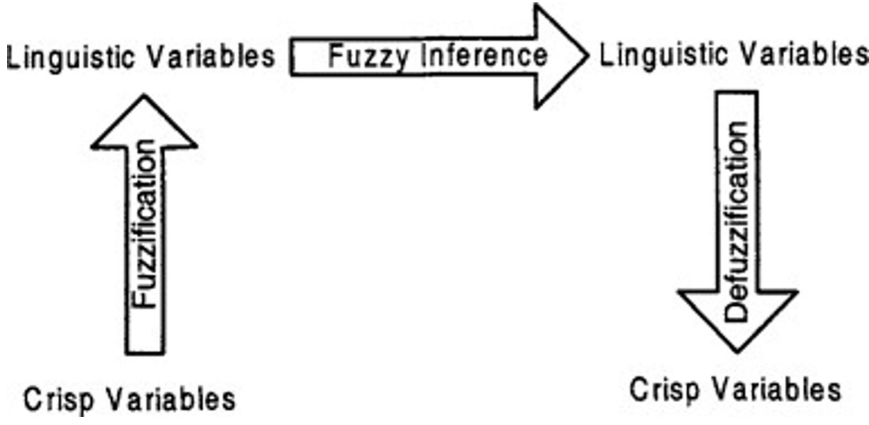

Figure 1. Structure of a fuzzy logic system.

moments of area as defined by:

$$
C^{\wedge}=\frac{\sum C_{i}(\mu c)}{\sum \mu c\left(C_{i}\right)},
$$

where $C_{i}(\mu c)$ is membership value in the membership function and $\mu c$ is center of membership function [10].

\section{Proposed Fuzzy Expert Model Domain}

This study focuses on the activities involved in the credit risk management departments in the Egyptian business banks that are working under the supervision of the Central Bank of Egypt and following the Egyptian financial laws issued in 1958 and updates.

\subsection{Proposed Model Architecture}

The proposed expert model is designed as a fuzzy expert system that consists of the following components shown in Figure 2.

- Knowledge base: Extracted through the knowledge acquisition process from the bank periodicals and experts in the domain are then transferred into the knowledge base.

- Inference Engine: Matches the facts with the rules' condition to determine which rules to apply and the most appropriate rule for its operation and then performs the associated procedure.

- Working Memory: Client and non-financial databases and facts used with the application.

- User Interface: Facilitates the method of interaction between the person and model, which is used to input the client's data, credit risk management, employees' inquiries or other financial data, and receiving the output. 


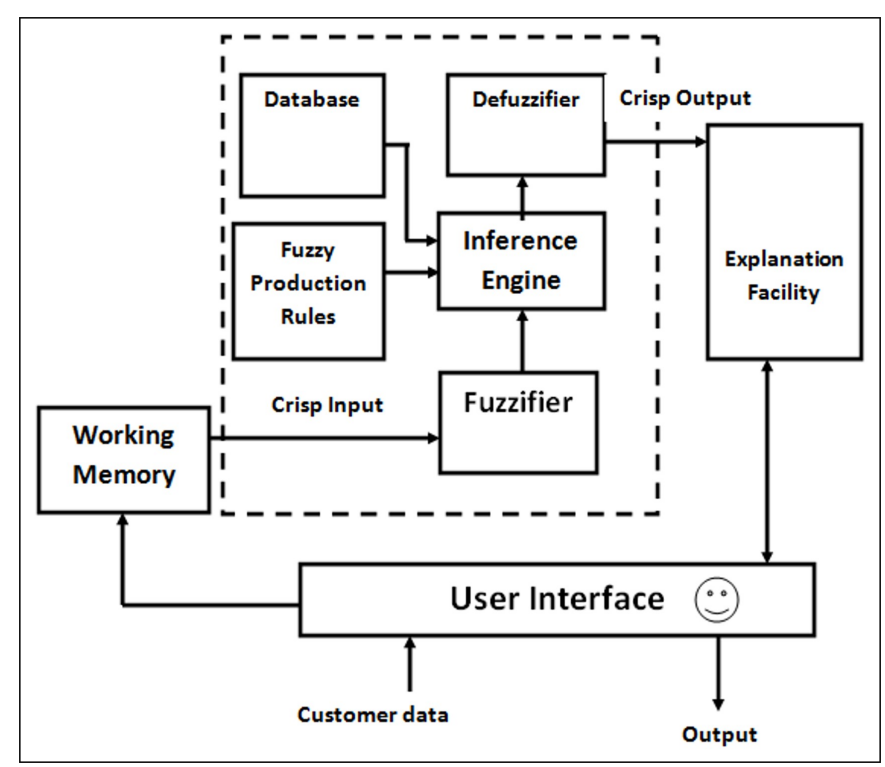

Figure 2. Proposed fuzzy model.

- Explanation Facilities: Inquiries procedures in the model to help the user ask questions or inquire about the knowledge base, justify the decision-making process, and follow it.

- Fuzzifier: Accepts the numerical data (Crisp Input) and converts it to a linguistic variable.

- Defuzzification: Converts the result from the inference engine into fuzzy crisp output.

\subsection{The Model Functions according to the Following Steps}

Step 1. The credit officer who runs the model will enter the client's main data and the project data in the specific forms in the user interface.

Step 2. They will then complete the loan request from the client to identify all information about the requested loan and the facilities that are suitable to the client and the bank.

Step 3. After finishing, the decision maker will complete collecting the non-financial factors of the client to study the actual situation of the client and project.

Step 4. . The queries department will collect the information about the client and project them to determine if the company's activity is profitable and the extra client dealing with banks are good.
Step 5. Depending on the rules of identification algorithm, results lead the non-financial algorithm to be activated using the inference engine to search through the involved fuzzy rules database to find the suitable decision that covers the client case while taking the queries department report into consideration.

Step 6. If the client request is refused, the process is finished. If it is accepted, the algorithm successfully finds the suitable decision with suitable facilities. The model is stopped, and the result is displayed.

\section{Fuzzy Expert System Development}

The Fuzzy Logic Toolbox is a set of functions built in the MATLAB digital computing environment. It provides the tools needed to create and edit the fuzzy interference system with the MATLAB framework or integrate the fuzzy system into simulation with reality.

\subsection{The Model Input Data}

\subsubsection{Data collection}

The researchers collected various data related to the system in credit departments in the Egyptian banks according to the rules of the central Egyptian bank from different resources such as professional experts in banks, banking and credit risk management textbooks, and monthly periodicals of the Central Bank of Egypt [11].

\subsubsection{Database structure}

The researchers created a relational database consisting of many tables including client data, loan data, non-financial rules, and all tables that include the extracted data concerning previous clients' cases, which were clarified by the professional experts in credit departments.

The researchers created a fuzzy rule database using the MATLAB application that can accept the linguistic variables of non-financial factors: Official Experience, Project Funding, Company's Activity, and Client Personality (Tables 1 and 2). The results were exported to the relational database to be interchanged to numerical variables and produce the final report to the decision maker as shown in Figure 3. The researchers used the relational data base for the following reasons:

(i) There are many relations between tables that ought to be connected. 
Table 1. Examples of management rules

\begin{tabular}{|c|c|c|c|}
\hline $\begin{array}{l}\text { No. } \\
\text { of } \\
\text { rule }\end{array}$ & \multicolumn{3}{|c|}{ Rule } \\
\hline \multirow{5}{*}{1} & IF & Official Experience is High & $(0.9)$ \\
\hline & AND & Project Funding is Adequate & $(0.8)$ \\
\hline & AND & Project Stuff is Large & $(0.85)$ \\
\hline & THEN & Management Efficient is Hig & [cf 0.9] \\
\hline & $\mathrm{CF}(\mathrm{H}$, & $\mathrm{E} 1 \cap \mathrm{E} 2 \cap \mathrm{E} 3)=\min [0.9,0.8,0.85$ & $* 0.9=0.8 * 0.9=0.72$ \\
\hline \multirow{5}{*}{2} & IF & Official Experience is High & $(0.9)$ \\
\hline & AND & Project Funding is Marginal & $(0.5)$ \\
\hline & AND & Project Stuff is Average & $(0.55)$ \\
\hline & THEN & Management Efficient is Hig & [cf 0.9] \\
\hline & $\mathrm{CF}(\mathrm{H}$, & $\mathrm{E} 1 \cap \mathrm{E} 2 \cap \mathrm{E} 3)=\min [0.9,0.5,0.55$ & $* 0.9=0.5 * 0.9=0.42$ \\
\hline \multirow{5}{*}{3} & IF & Official Experience is High & $(0.6)$ \\
\hline & AND & Project Funding is Adequate & $(0.8)$ \\
\hline & AND & Project Stuff is Average & $(0.55)$ \\
\hline & THEN & Management Efficient is Hig & [cf 0.9] \\
\hline & $\mathrm{CF}(\mathrm{H}$, & $\mathrm{E} 1 \cap \mathrm{E} 2 \cap \mathrm{E} 3)=\min [0.6,0.8,0.55$ & $* 0.9=0.55 * 0.9=0.495$ \\
\hline \multirow{5}{*}{4} & IF & Official Experience is High & $(0.9)$ \\
\hline & AND & Project Funding is Marginal & $(0.5)$ \\
\hline & AND & Project Stuff is Large & $(0.85)$ \\
\hline & THEN & Management Efficient is Hig & [cf 0.9] \\
\hline & $\mathrm{CF}(\mathrm{H}$, & $\mathrm{E} 1 \cap \mathrm{E} 2 \cap \mathrm{E} 3)=\min [0.9,0.5,0.85$ & $* 0.9=0.5 * 0.9=0.45$ \\
\hline
\end{tabular}

(ii) The convenience of creating new tables of non-financial factors with the difference of client's nature and surrounding conditions.

The proposed model can be applied in the bank's branches by implementing the distributed databases, which are a set of networked computer databases at different sites. It can be managed by the main branch of the bank while appearing to the user as a single database.

\subsection{Fuzzy set of the Proposed Model}

Based on the knowledge of the experts in this field, the input and output variables selected for this research were explained by 24 linguistic variables. Table 3 presents a sample of the extent of the fuzzy value of each linguistic variable. During this process, the linguistic variables are evaluated using the triple membership function and accompanied by an associated membership degree ranging from 0 to 1 as shown in Figure 4.

The model provides the fuzzy rules to measure the nonfinancial aspects such as education and experience level, project activity, and economic and market conditions, which the bank
Table 2. Examples of management rules

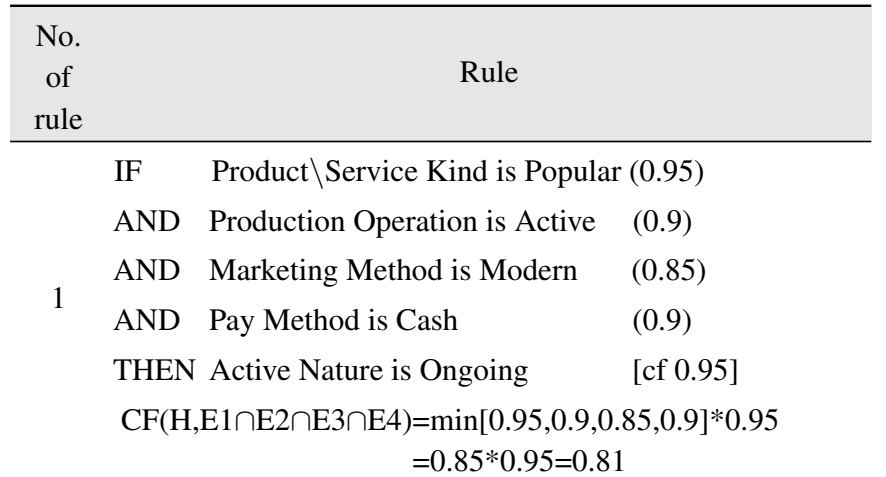

\begin{tabular}{|c|c|c|c|}
\hline \multirow{6}{*}{2} & IF & Product $\backslash$ Service Kind is Popula & $r(0.95)$ \\
\hline & AND & Production Operation is Active & $(0.9)$ \\
\hline & AND & Marketing Method is Modern & $(0.85)$ \\
\hline & AND & Pay Method is Premium & $(0.6)$ \\
\hline & THEN & Active Nature is Ongoing & [cf 0.95] \\
\hline & $\mathrm{CF}(\mathrm{H}$ & $\begin{aligned}\mathrm{E} 1 \cap \mathrm{E} 2 \cap \mathrm{E} 3 \cap \mathrm{E} 4) & =\min [0.95,0.9,0 \\
& =0.6^{*} 0.95=0.57\end{aligned}$ & $.85,0.61 * 0.95$ \\
\hline \multirow{6}{*}{3} & IF & \multicolumn{2}{|c|}{ Product $\backslash$ Service Kind is Popular (0.95) } \\
\hline & AND & Production Operation is Active & $(0.9)$ \\
\hline & AND & Marketing Method is Normal & $(0.7)$ \\
\hline & AND & Pay Method is Cash & $(0.9)$ \\
\hline & THEN & Active Nature is Ongoing & [cf 0.95] \\
\hline & $\mathrm{CF}(\mathrm{H}$ & $\begin{aligned}\mathrm{E} 1 \cap \mathrm{E} 2 \cap \mathrm{E} 3 \cap \mathrm{E} 4) & =\min [0.95,0.9,0 \\
& =0.7 * 0.95=0.67\end{aligned}$ & $.7,0.9] * 0.95$ \\
\hline \multirow{6}{*}{4} & IF & \multicolumn{2}{|c|}{ Product $\backslash$ Service Kind is Popular (0.95) } \\
\hline & AND & Production Operation is Active & $(0.9)$ \\
\hline & AND & Marketing Method is Normal & $(0.7)$ \\
\hline & AND & Pay Method is Premium & $(0.9)$ \\
\hline & THEN & Active Nature is Ongoing & [cf 0.95] \\
\hline & $\mathrm{CF}(\mathrm{H}$ & $\begin{aligned}\mathrm{E} 1 \cap \mathrm{E} 2 \cap \mathrm{E} 3 \cap \mathrm{E} 4) & =\min [0.95,0.9,0 \\
& =0.6 * 0.95=0.57\end{aligned}$ & $.7,0.6\rceil^{*} 0.95$ \\
\hline \multirow{6}{*}{5} & IF & \multicolumn{2}{|c|}{ Product $\backslash$ Service Kind is Popular (0.95) } \\
\hline & AND & Production Operation is Active & $(0.9)$ \\
\hline & AND & Marketing Method is Old & $(0.45)$ \\
\hline & AND & Pay Method is Cash & $(0.9)$ \\
\hline & THEN & Active Nature is Ongoing & [cf 0.95] \\
\hline & $\mathrm{CF}(\mathrm{H}$, & $\begin{aligned}\mathrm{E} 1 \cap \mathrm{E} 2 \cap \mathrm{E} 3 \cap \mathrm{E} 4) & =\min [0.95,0.9,0 \\
& =0.45^{*} 0.95=0.4\end{aligned}$ & $\begin{array}{l}.45,0.9] * 0.95 \\
3\end{array}$ \\
\hline
\end{tabular}

use to judge the client (always updated) as shown in Figure 5 [9].

\subsection{Fuzzy Production Rules of the Proposed System}

There are 84 variables as system input parameters. These were used to create 241 fuzzy production rules. Rules in the model 


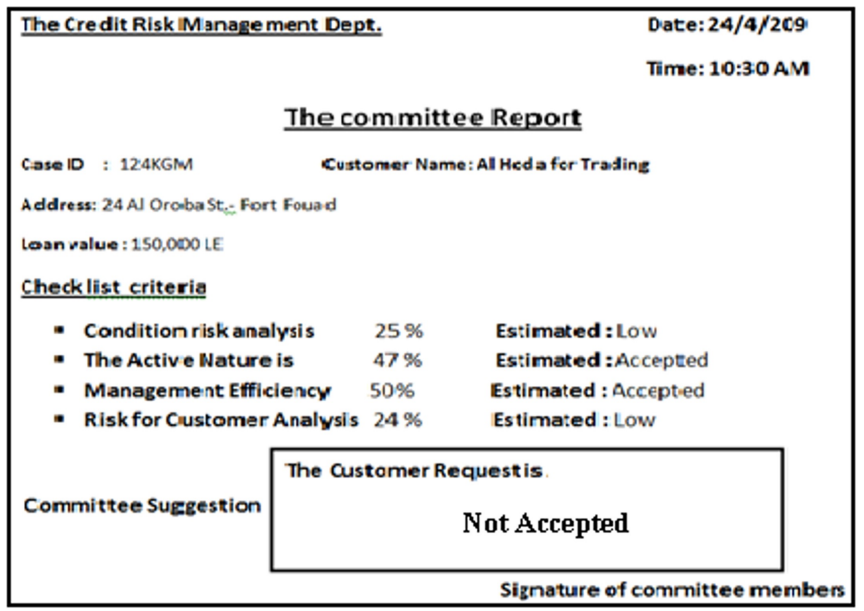

Figure 3. Snapshot credit risk management department report.

Table 3. Linguistic variables [9]

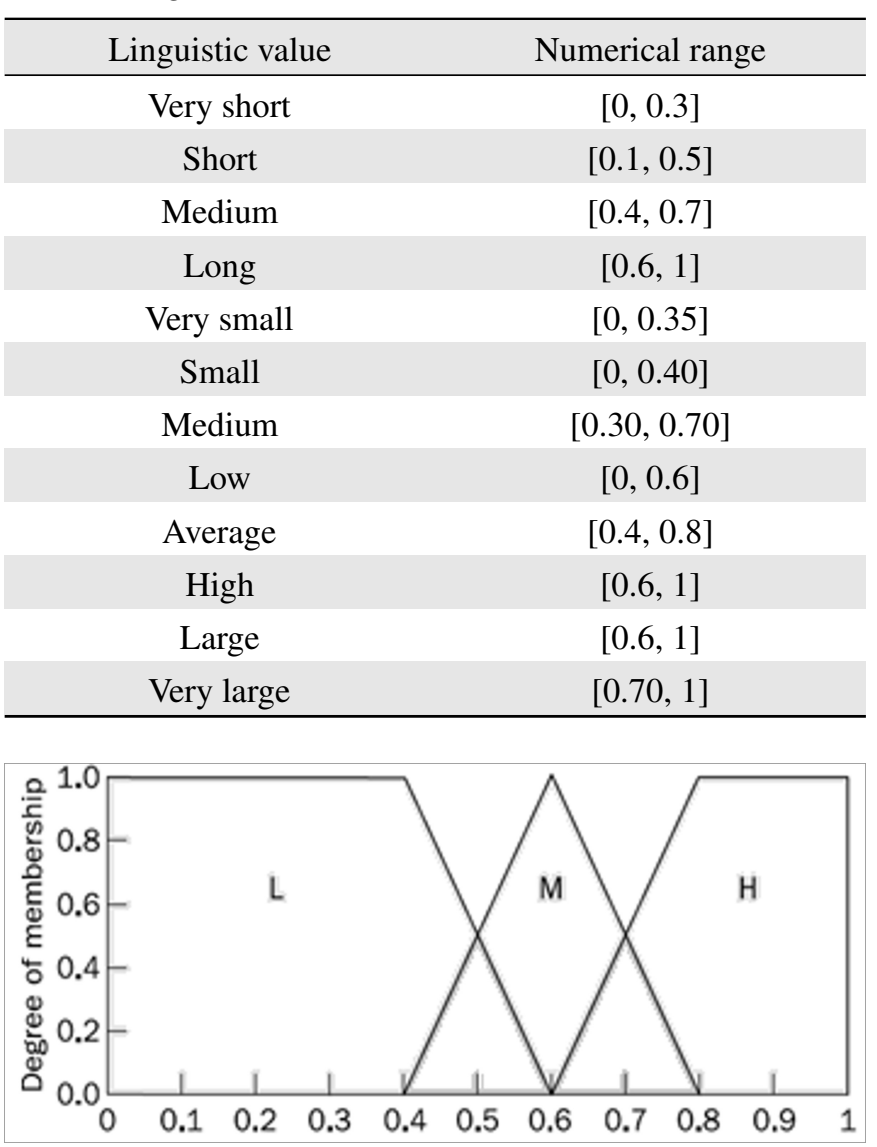

Figure 4. Fuzzy sets of membership degree.

knowledge base are structural to reflect the nature of human thinking in the field of the domain. Tables 1 and 2 present some examples of rules.

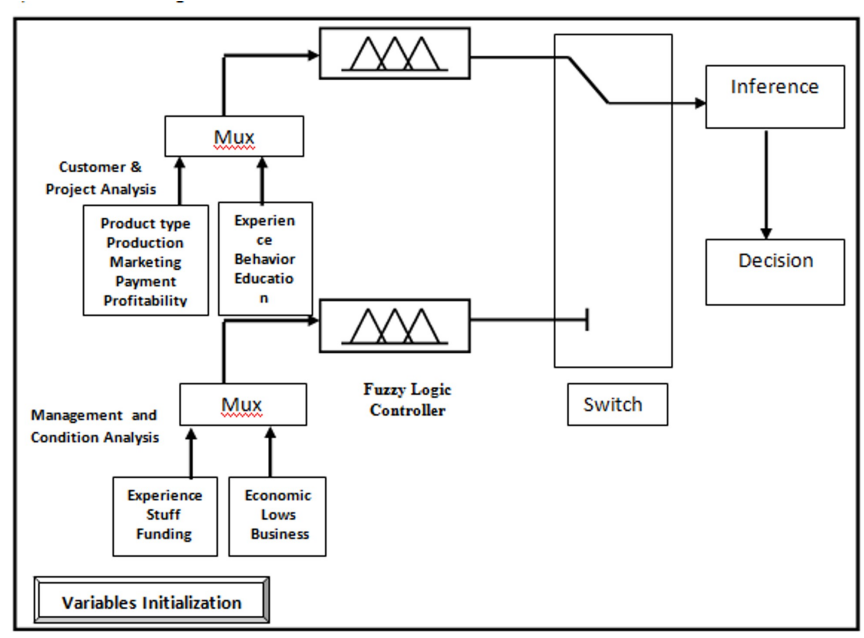

Figure 5. Non-financial fuzzy factors of the client.

\subsection{Validation of Proposed Model}

To overcome the problems of the knowledge base validation and avoid errors in it, the researchers followed the methodologies listed below:

- Extract the knowledge base of the model from standard documents in the domain. The standard processes that created the model are assumed to have validated the knowledge in the standard. Referring to the textbooks and banking references used for building the knowledge base.

- Create a knowledge model under supervision of an expert (Credit Expert in QNB) and review the model with external experts (individually) and modify or expand the knowledge base according to their responses. Table 4 shows the knowledge base confidence level of the external experts; it is probably a good idea to ask at least four experts to verify each important assumption backing up the knowledge base. When four or more experts agree unanimously, the assumption is reasonably validated. A total of experts agreeing provides a high level of confidence in the assumption.

- Apply the proposed model in the credit department in one of the Egyptian banks to test the model.

\subsection{User Interface}

GUI tools are used to create, edit, and monitor fuzzy heuristics in the Fuzzy Logic Toolbox. In the proposed model, the interface consists of a set of forms built in Visual Studio .NET 2016 
Table 4. Experts' confidence level of model knowledge base

\begin{tabular}{cc}
\hline Expert No. & Confidence level (\%) \\
\hline 1 & 80 \\
2 & 89 \\
3 & 78 \\
4 & 90 \\
5 & 92 \\
\hline
\end{tabular}

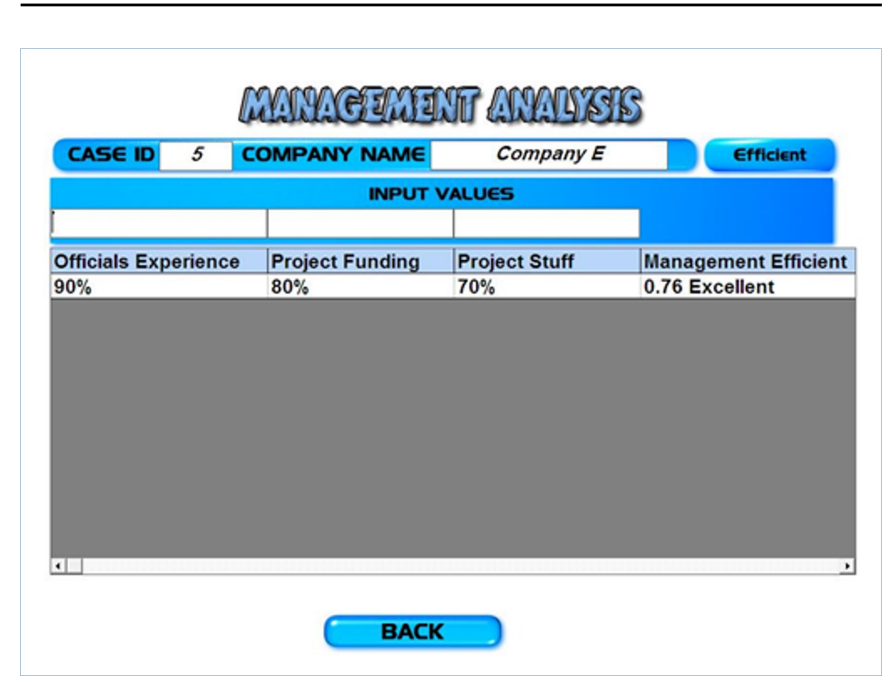

Figure 6. Snapshot management analysis.

because it is considered a flexible and a common software. The user can input the raw data needed for a consultation. Once the user completes a form, the data is translated into a format that can be understood by the inference engine. When the inference engine reaches a result, the user interface returns this information in natural language so that it can be understood by the user (Figures 3 and 6). The user may have information regarding a specific result and the interface can provide additional explanations about how the inference engine reached this conclusion.

\section{Results}

Due to many considerations such as laws, security issues and so on, it was difficult to get any public banks to agree to use the proposed model in a practical setting in the credit load department. The bank's administration allowed the researchers to obtain and study the historical data of the previous year, and only offered a set of available historical client cases (200 banks 603084102 approved clients separated on 8 moths). 67 successful payment clients, and 33 defaulted clients. The bank accepted the requested loans on a past period from 1/1/2017 to
Table 5. Client sample

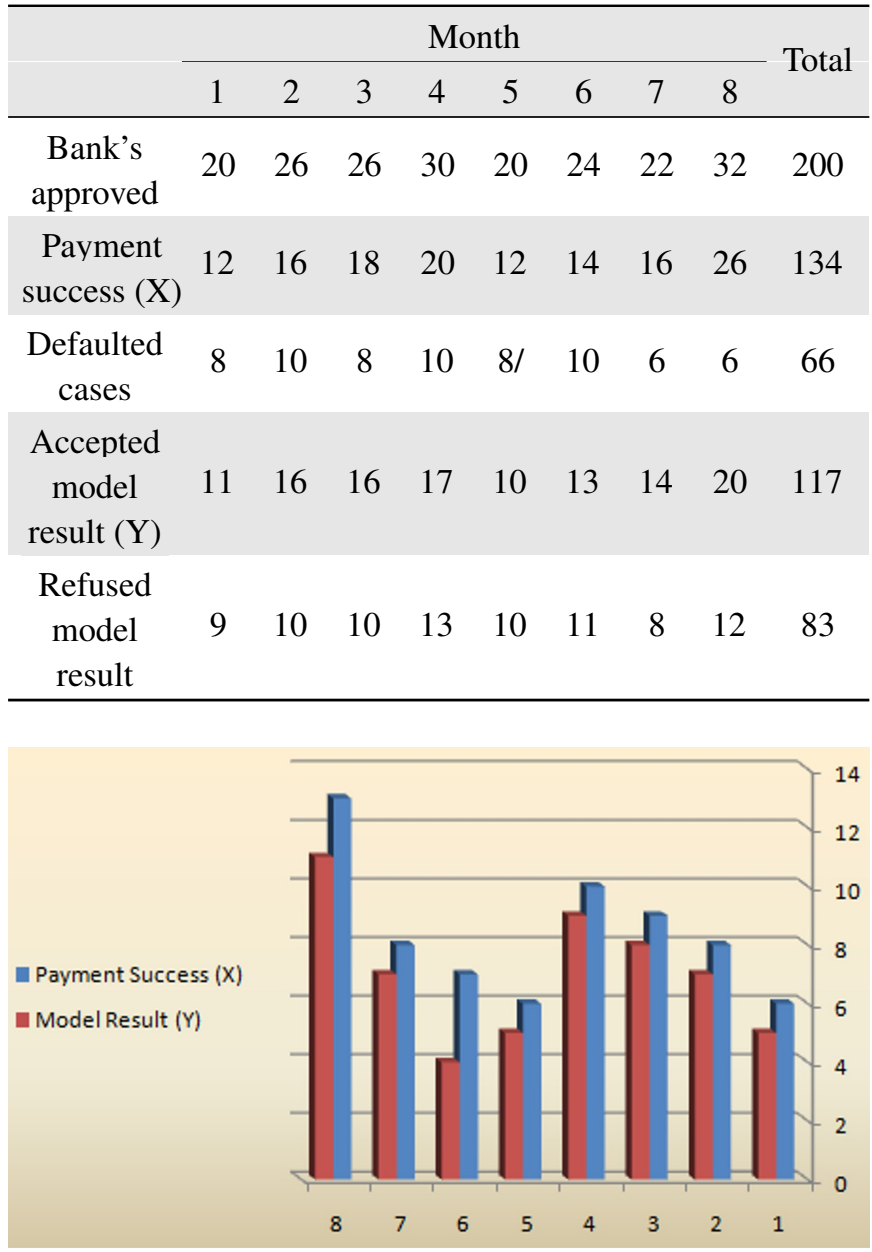

Figure 7. Deference between bank cases and model cases.

\section{$31 / 12 / 2017$}

By applying the proposed model on these clients for testing the model, the following results were obtained. Table 5 reports the numbers of classified clients in the sample and Figure 7 illustrates the difference between bank and model clients.

- The model classified 117 clients as accepted is 117 clients.

- The model refused 83 clients (from 200 clients) from the chosen sample and classified them as defaulted.

- The 83 clients that are rejected by the proposed model include 66 actual clients that had been classified as defaulted and were unable to repay the fixed installments on their due dates. 


\section{Evaluation of Proposed Model}

To calculate the success average between the bank's actual clients and the number predicted by the model, the correlation factor method is used. The number of clients that the model classified as defaulted is reported in Table 6. Correlation Factor is defined as "the amount of deviation in a measurement that is accounted for in the calibration process." It is a statistical measure of the interdependence of two or more random variables. Fundamentally, the value indicates how much of a change in one variable is explained by a change in another.

The researcher applied the following mathematical equation to calculate the result [12]:

$$
\begin{aligned}
& R=\frac{n\left(\sum x y\right)-\left(\sum x\right)\left(\sum y\right)}{\sqrt{n \sum x^{2}-\left(\sum x\right)^{2}} \sqrt{n \sum y^{2}-\left(\sum y\right)^{2}}}, \\
& N=\text { number of months (8), } \\
& X=\text { number of successful payment clients (134), } \\
& Y=\text { number of clients the model accepted (117). }
\end{aligned}
$$

$$
\begin{aligned}
& R=\frac{8 * 2062-(134 * 117)}{\sqrt{8 * 2396-(134)^{\wedge} 2} \sqrt{8 * 1787-(117)^{\wedge} 2}}, \\
& R=\frac{16496-1568}{\sqrt{19168-17956} \sqrt{14296-13689}} \\
& R=\frac{818}{\sqrt{1212} \sqrt{607}}=\frac{818}{857.7}=0.953 .
\end{aligned}
$$

\subsection{Applying the Defuzzification}

The researchers used MATLAB membership functions and obtained the following results:

(i) Risk for condition analysis is Low (025)

(ii) Active Nature is Acceptable (0.47)

(iii) Management Efficiency is Acceptable (0.50)

(iv) Risk for client analysis is Low (0.24)

Then, applying the defuzzification using $\mathrm{CoG}$ formula (2) as previously mentioned, the result is as shown in Figure 3, which is not acceptable for the model.

\section{Discussion of Results}

Based on the analysis of the results, this study reaches the following conclusions:

- The bank approved a total of 200 clients. A total of 134 clients were considered successful payment clients (who repaid the total loan to the bank). The model classified

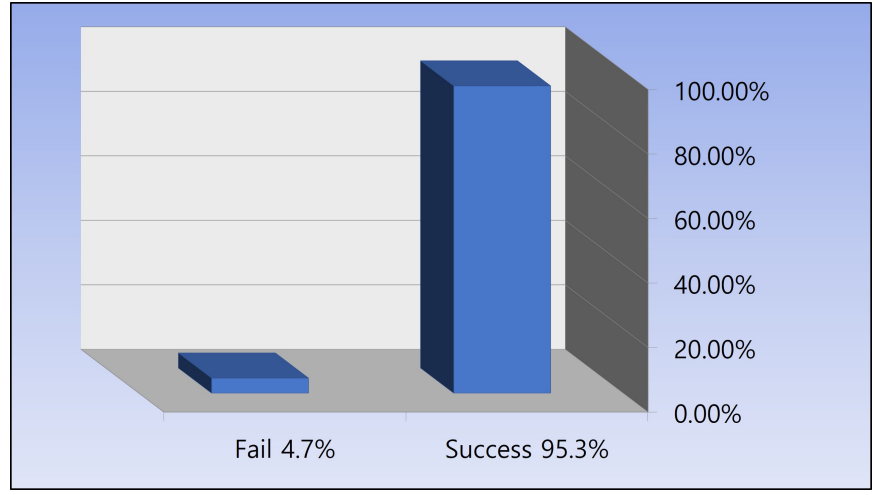

Figure 8. Model dependency.

117 clients as accepted and predicted that they would pay the loan. The model rejected 83 clients from the chosen sample and classified them as defaulted, including $66 \mathrm{ac}-$ tual clients who were unable to pay the fixed installments on their due dates.

- Based on the above findings, the model is found to be 95.3\% efficient. The slight accuracy difference between the results of the proposed model and the actual reality as shown in Figure 8 is $4.7 \%$ (i.e., 17 clients who were rejected by the model and paid off their loans in full). This means that to be more accurate, the model needs more developing in terms of analysis of non-financial factors.

- When the actual payment position of refused clients was examined, they were found to default and did not pay the due premium to the bank on their due dates.

- According to the experts' views, the result of a classification accuracy rate of $95.3 \%$ is a very good result in terms in model evaluation.

\section{Comparison between the Proposed Model and Another Models}

Soares et al. [13] found that his model was able to give a prediction classification rate with an accuracy of $80 \%$.

Martin et al. [14] implemented a fuzzy model to predict defaulted clients using the expert knowledge that was applied in fuzzy rules with an accuracy rate of $88 \%$ in one model. In a hybrid model, which used neuro-fuzzy and genetic algorithms, the accuracy rate was $73.6 \%$, but with extra and different input variables. 


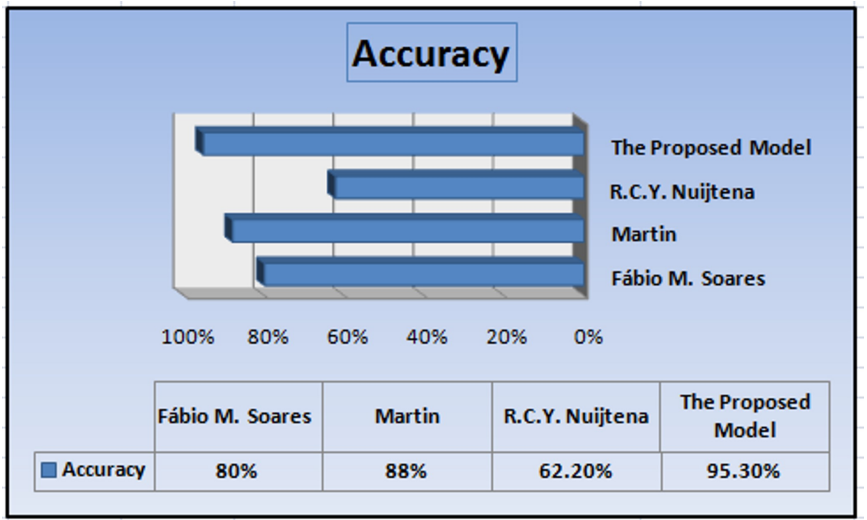

Figure 9. Accuracy of different models.

Nuijten et al. [15] developed a fuzzy model with an accuracy rate of $62.2 \%$, which was slightly better than a random system may achieve.

In the proposed model, the accuracy rate is $95.3 \%$, a better rate than the aforementioned models. The model was improved by creating a fuzzy knowledge base that includes all the linguistic rules used by decision makers to judge the clients. These rules did not have any clear ratios to measure them, so the researchers are working on improving this. The result is shown in Figure 9.

\section{Conclusion}

The duty of credit risk management departments becomes more complicated due to the consideration of financial laws and business banks' articles and procedures. In addition, globalization increases the need for flexibility, and it becomes more challenging. Automation of credit risk management is another challenge in the future for the development of generic diagnostic architectures that can potentially use a variety of analysis and predicting techniques of clients' financial and non-financial position and demand, which can be applied to all the credit risk management departments in all types of banks.

The proposed model has been programmed from human expertise and the documents of the specific domain. Although the application is not large, it is rather complicated, it has a high performance, and has an accuracy rate of $95.3 \%$, which experts considered sufficient. The proposed model is not considered a complete solution. Human expert's intelligence is still the final judgment; however, it is considered as a starting point to help the decision maker in credit departments in banks to make the right decision about approving loans or rejecting client's request.

The main interest in developing the model is to ensure the accuracy of all its recommendations in difficult as well as simple cases, thereby obtaining a good understanding of the field and an accurate characterization of this understanding in a form that can be maintained. Clear and proven logical programming is used for the purposes of this research. This approach was sufficiently flexible to allow for the application of the model to easily accommodate the ongoing modifications into the initial designs.

\section{Conflict of Interest}

No potential conflict of interest relevant to this article was reported.

\section{References}

[1] Central Bank of Egypt, "Annual Report of Financial and Economic for 2018/2019," 2019, Available https://www. cbe.org.eg/en/Pages/default.aspx

[2] Moody's Investors Service, "Rating Action: Moody's takes rating action on 13 Turkish corporates following sovereign downgrade," 2018, Available https://www.moodys.com/research/Moodys-takesrating-action-on-13-Turkish-corporates-followingsovereign--PR_388019

[3] W. Siler and J. J. Buckley, Fuzzy Expert Systems and Fuzzy Reasoning. Hoboken, NJ: John Wiley \& Sons Inc., 2004.

[4] N. R. Darwish and A. S. Abdelghany, "A fuzzy logic model for credit risk rating of Egyptian commercial banks," International Journal of Computer Science and Information Security, vol. 14, no. 2, pp. 11-18, 2016.

[5] S. Brkic, M. Hodzic, and E. Dzanic, "Fuzzy logic model of soft data analysis for corporate client credit risk assessment in commercial banking," in Proceedings of the 5th Scientific Conference with International Participation “Economy of Integration” (ICEI), 2017, Tuzla, Bosnia.

[6] M. G. Asogbon, O. Olabode, O. C. Agbonifo, O. W. Samuel, and V. I. Yemi-Peters, "Adaptive neuro-fuzzy inference system for mortgage loan risk assessment," International Journal of Intelligent Information Systems, vol. 5, no. 1, pp. 17-24, 2016. https://doi.org/10.11648/j.ijiis. 20160501.13 
[7] S. Mammadli, "Fuzzy logic based loan evaluation system," Procedia Computer Science, vol. 102, pp. 495-499, 2016. https://doi.org/10.1016/j.procs.2016.09.433

[8] E. Ebrahimi, M. R. Fathi, and H. R. Irani, H. R. ?A new hybrid method based on fuzzy Shannon's Entropy and fuzzy COPRAS for CRM performance evaluation (Case: Mellat Bank)," Iranian Journal of Management Studies, vol. 9, no. 2, pp. 333-358, 2016.

[9] N. Michael, Artificial Intelligence a Guide to Intelligent Systems, 2nd ed. Harlow, UK: Addison-Wesley, 2004.

[10] K. Wang, "Computational intelligence in agile manufacturing engineering," in Agile Manufacturing The 21st Century Competitive Strategy. Oxford, UK: Elsevier, 2001, pp. 297-315. https://doi.org/10.1016/B978-0080435671/50016-4

[11] Central Bank of Egypt, "CBE Library," Available https:// www.cbe.org.eg/en/AboutCBE/Pages/CBELibrary.aspx

[12] http://www.toolingu.org/definition-350115-5905correction-factor.html

[13] F. M. Soares, O. S. R. Neto, and H. H. Barbosa, "A simple fuzzy system applied to predict default rate," in Fuzzy Logic: Tool for Getting Accurate Solutions. Rijeka, Croatia: InTech, 2015, pp. 1-26. https://doi.org/10.5772/60079

[14] A. Martin, V. Gayathri, G. Saranya, P. Gayathri, and P. Venkatesan, "A hybrid model for bankruptcy prediction using genetic algorithm, fuzzy c-means and MARS," International Journal on Soft Computing, vol. 2, no. 1, pp. 12-24, 2011

[15] R. Nuijten, U. Kaymak, P. Van Gorp, M. Simons, P. Van Den Berg, and P. Le Blanc, "Fuzzy modeling to 'understand' personal preferences of mHealth users: a case study," in Proceedings of the 11th Conference of the European Society for Fuzzy Logic and Technology (EUSFLAT), Prague, Czech Republic, 2019, pp. 558-565. https://dx.doi.org/10.2991/eusflat-19.2019.77 603086074

[16] J. Mockor, "Powerset theory of fuzzy soft sets," International Journal of Fuzzy Logic and Intelligent Systems, vol. 20, no. 4, pp. 298-315, 2020. https://doi.org/10.5391/ IJFIS.2020.20.4.298

[17] A. B. Khalifa and H. Frigui, "Multiple instance Mamdani fuzzy inference," International Journal of Fuzzy Logic and Intelligent Systems, vol. 15, no. 4, pp. 217-231, 2015. https://doi.org/10.5391/IJFIS.2015.15.4.217

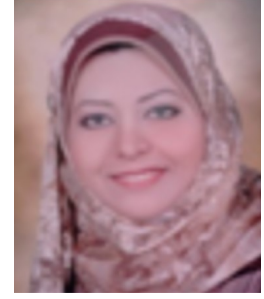

Noha Ibrahem Hasanis a Lecture Assistant and a Ph.D. candidate at the Department of Information System at Sadat Academy for Administration Science, Egypt. She majored in artificial intelligence in her master's study. She has been working on research related to fuzzy logic and prediction in the banking sector.

E-mail: noha.hassan2020@sadatacademy.edu.eg

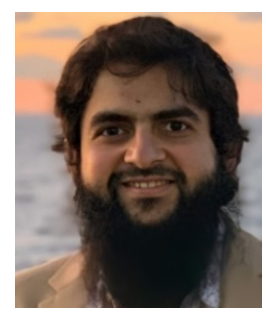

Haitham Elghareeb is an Associate Professor of Information Systems at the Faculty of Computers and Information Sciences, Mansoura University, Egypt. He is a member of many distinguished computer organizations, reviewer for different highly recognized academic journals, contributor to opensource projects, and the author of different internationally published books. Haitham is interested in ERP systems, intelligent information systems, and systems integration.

E-mail:

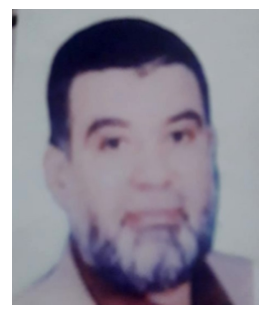

Farahat Farag Farahat is a Professor of Information System at Sadat Academy for Administration Science, Egypt. He is interested in Systems Analysis and design, and Advanced Data base systems and Object-Oriented Database.

E-mail:

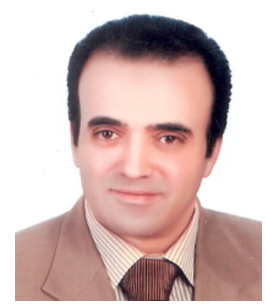

Ahmed AboElfotouh is a Professor of Information Systems at the Faculty of Computers and Information Sciences, Mansoura University, Egypt. Vice Dean for Postgraduate and Research at the Faculty of Computer \& Information Sciences. Ahmed is interested in decision support systems, intelligent information systems, geographic information systems, and management information systems.

E-mail: 